\title{
THE
}

\section{A systematic review of integrative medicine for opioid withdrawal}

\author{
Caroline Kruszecki \\ University of Rhode Island \\ R. Cameron \\ University of Rhode Island \\ Anne L. Hume \\ University of Rhode Island, alhume@uri.edu \\ Kristina E. Ward \\ University of Rhode Island, kward@uri.edu
}

Follow this and additional works at: https://digitalcommons.uri.edu/php_facpubs

The University of Rhode Island Faculty have made this article openly available.
Please let us know how Open Access to this research benefits you.

This is a pre-publication author manuscript of the final, published article.

Terms of Use

This article is made available under the terms and conditions applicable towards Open Access Policy Articles, as set forth in our Terms of Use.

\section{Citation/Publisher Attribution}

Kruszecki, C., Cameron, C. R., Hume, A. L., \& Ward, K. E. (2021). A systematic review of integrative medicine for opioid withdrawal. Journal of Substance Abuse Treatment, 125, 108279. doi: 10.1016/ j.jsat.2021.108279

Available at: https://doi.org/10.1016/j.jsat.2021.108279

This Article is brought to you for free and open access by the Pharmacy Practice at DigitalCommons@URI. It has been accepted for inclusion in Pharmacy Practice Faculty Publications by an authorized administrator of DigitalCommons@URI. For more information, please contact digitalcommons-group@uri.edu. 


\section{A systematic review of integrative medicine for opioid withdrawal}

Kruszecki C, Cameron CR, Hume AL, Ward KE

University of Rhode Island, College of Pharmacy

*Corresponding Author: Courtney R. Cameron; email: crcameron5@gmail.com

Financial Support: None

Keywords: withdrawal management, acute opioid withdrawal treatment, heroin withdrawal, complementary and alternative medicine, opioid use disorder therapy, natural medicine

Manuscript Word Count: 4618 


\begin{abstract}
:
Introduction: The United States has been battling an opioid epidemic for decades. As substance use disorders have grown, so too has investigation into treatment options, including integrative medicine approaches, for managing opioid withdrawal symptoms (OWS).
\end{abstract}

Objectives: This systematic review sought to assess the use of integrative medicine approaches for the alleviation of OWS in patients dependent on opioids and to summarize the available data.

Methods: The authors searched using synonyms for opioids, substance use disorder, and integrative medicine and standardized searches in Embase, PubMed, and Cochrane Library. We also hand searched references for systematic reviews. This review did not include articles that could not be obtained as full-text publications via interlibrary loan. The review also excluded studies with interventions involving acupuncture because multiple systematic reviews on this approach already exist. In addition, we also excluded studies of therapy for opioid maintenance. We evaluated studies for inclusion based on the Jadad criteria. We compared opioid withdrawal outcomes of the studies to determine the efficacy of integrative medicine approaches.

Results: The authors identified a total of 382 unique publications initially for possible inclusion through systematic searches. After applying inclusion and exclusion criteria, five studies met Jadad criteria. The authors identified an additional two studies for inclusion via hand searching. A total of seven studies included interventions consisting of passionflower, weinicom, fu-yuan pellet, jinniu capsules, tai-kang-ning, dynorphin, and l-tetrahydropalmatine. Analyzing the articles was difficult given the varied scoring methods they used to quantify opioid withdrawal 
symptoms and the small sample sizes in the trials. Most showed evidence that supported integrative medicine approaches for OWS, although the strength of evidence was limited because of sample sizes.

Conclusions: This review found evidence of multiple integrative medicine approaches for opioid withdrawal symptoms. Well-designed randomized controlled trials should assess the efficacy of integrative medicine for improvement in OWS. 


\subsection{Introduction:}

In 2017, 191 million opioid prescriptions were written in the United States, the first time in ten years that the number of prescriptions written for opioids has been below 200 million per year. ${ }^{1}$ Although progress is being made toward reducing the number of opioids prescribed in the United States in light of the opioid epidemic, the opioid prescribing rate remains high at 58.7 prescriptions per 100 persons. ${ }^{1}$ As patients and prescribers become increasingly aware of opioid use disorder, the identification of effective withdrawal treatments is vital to patient safety and comfort.

Opioid withdrawal symptoms (OWS), including agitation, insomnia, diaphoresis, tachycardia, and many others, can be debilitating for many patients. ${ }^{2,3}$ Symptoms can start as early as six hours after the last dose of an opioid and peak around 72 hours after last use. ${ }^{2}$ Although OWS may not be life-threatening, unassisted withdrawal can increase the risk of relapse. $^{2}$

Fear of opioid withdrawal syndrome is a contributing factor to the cycle of abuse in individuals who misuse opioids. ${ }^{4}$ In current practice, opioid withdrawal is managed either through the gradual taper of opioid agonists, such as methadone or buprenorphine, or through the use of nonopioids, such as clonidine for symptoms. ${ }^{3}$ Alpha-2 agonists, such as lofexidine, FDA approved for OWS, and clonidine, used off label, are sometimes combined with other prescription medications to combat specific withdrawal symptoms. For example, benzodiazepines are sometimes used for anxiety during withdrawal, although they should be used with caution due to known risk of dependence.$^{3}$

Although buprenorphine and clonidine are useful in diminishing symptoms, some individuals may be interested in integrative medicine approaches for OWS. However, despite 
increased interest in integrative medicine for OWS, clear guidance and evidence is lacking. The purpose of this systematic review is to identify and evaluate available evidence regarding integrative medicine for opioid withdrawal symptoms.

\subsection{Methods:}

1.1.1 Protocol and Registration: The Preferred Reporting Items for Systematic Reviews and Meta-Analyses statement was used to conduct this systematic review.

1.1.2 Literature Search: Three databases, Pubmed, Embase, and Cochrane Library, were searched for studies investigating the efficacy of integrative medicine on symptoms of opioid withdrawal. The search strategy consisted of using a combination of synonyms from three baseterm categories, including "opioids", "substance use disorder", and "integrative medicine". Thirty combinations were searched systematically in each database and included one term from the integrative medicine category, one term from the substance-use-disorder category, and the standard opioid term sequence. All three categories were connected using the Boolean term “AND”. Medical Subject Headings terms were used for Pubmed and Cochrane Library, while Emtree terms were used for Embase. Specific terms were determined via the database's preferred terminology. For the integrative-medicine-terms category, the terms "Integrative Medicine", "Complementary Therapies" (Emtree preferred term: "Alternative Medicine"), "Medicine, Chinese" (Emtree preferred term: “Chinese Medicine"), "Biological Products" (Emtree preferred term: "Natural Products"), and "Herbal Medicine" were searched systematically. For the substance-use-disorder category, the terms "Substance Withdrawal Syndrome" (Emtree preferred term: "Withdrawal Syndrome"), "Opioid-Related Disorders" (Emtree preferred term: Opioid Use Disorder"), and "Substance-Related Disorders" (Emtree preferred term: "Drug Dependence") 
were used. Additionally, "Opioid Withdrawal" and "Detoxification AND Opiate" were used in Emtree, but no corresponding term was found in the Medical Subject Headings terms database. For the opioid category, "Heroin", "Morphine”, “Analgesics, Opioid” (Emtree preferred term: "Opiate"), "Codeine", and "Narcotics" (Emtree preferred term: "Narcotic Agent") were utilized for each search as a sequence connected by the Boolean term "OR". The studies were filtered for human subjects, the English language, and the dates January 1, 1968 - January 1, 2019. Articles that evaluated the use of acupuncture for opioid withdrawal were excluded from this systematic review because of the comprehensive body of data available when compared to the results of other, lesser-known integrative medicine approaches. After the initial search outlined above was completed, a hand search of the references was conducted to gather any additional potential pertinent articles.

1.1.3 Eligibility: Two authors (CC and $\mathrm{CK})$ used titles and abstracts to screen articles' findings from the three databases. Only randomized controlled trials, case-control studies, or cohort studies that evaluated the efficacy of integrative medicine approaches on symptoms of opioid withdrawal in adults were included for analysis. Studies that focused on prescription medication as the test intervention or focused on symptoms during the maintenance phase of treatment were ineligible. Additionally, abstracts or citations were not considered for analysis if full-text English versions could not be obtained via interlibrary loan. 


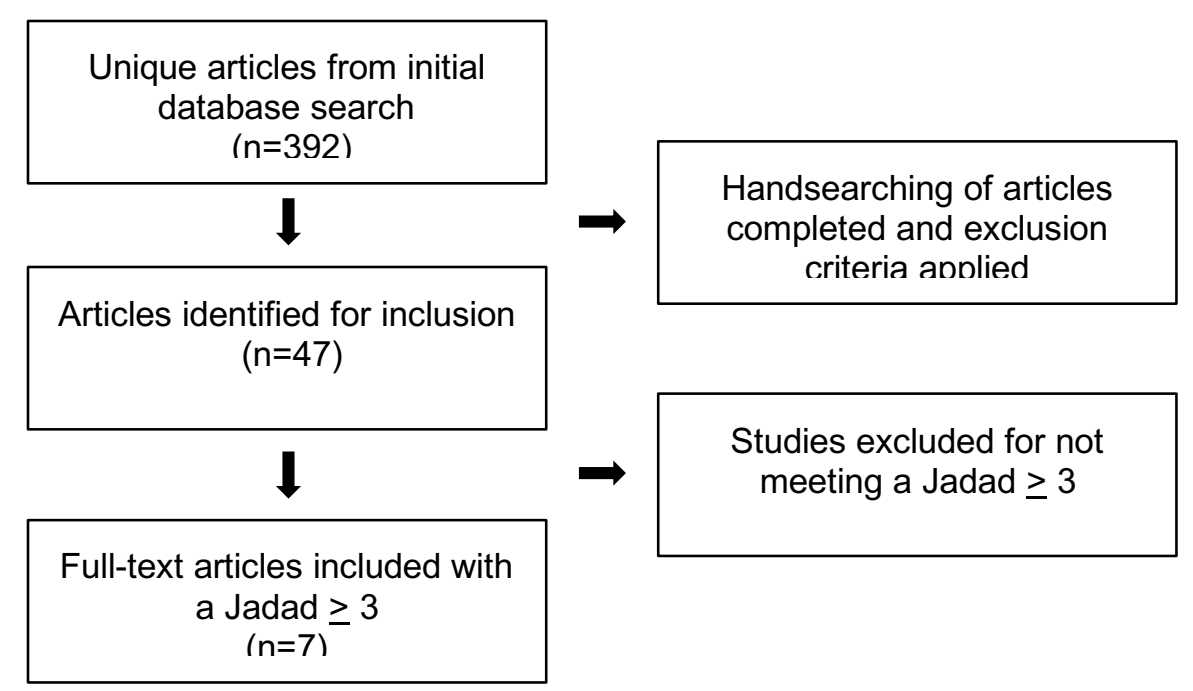

Fig. 1: Flow diagram of the systematic review process employed in this review.

\subsubsection{Study Selection, Data Extraction, and Analysis: Upon completion of initial}

eligibility screening, two authors (CC and $\mathrm{CK}$ ) independently scored full-text articles using a Jadad scale to assess the quality of the studies. The Jadad scale was chosen because it aims to reduce bias in studies by assessing elements of randomization, blinding, and participant accountability. ${ }^{5}$ Studies needed to meet a Jadad score of three or higher to be included.

Conflicts of any Jadad scores were resolved through independent scoring by two additional authors (KW and $\mathrm{AH})$. Once article selection was finalized, two authors ( $\mathrm{CC}$ and $\mathrm{CK}$ ) each independently extracted data to be subsequently verified by the remaining three authors. Researchers assessed study design, the specific integrative medicine approach, comparator group(s), participant population, assessment tools used in the trial, outcomes, and results.

Three hundred and ninety-two unique articles were found during the initial database search. After a hand-search for additional articles was completed and exclusion criteria were applied to all potential articles, 47 articles were considered for inclusion, but only seven met the Jadad criteria and were included in the review. 


\begin{tabular}{|c|c|c|c|c|c|c|}
\hline $\begin{array}{c}\text { Study } \\
\text { Information }\end{array}$ & $\begin{array}{c}\text { Patient } \\
\text { Population }\end{array}$ & $\begin{array}{c}\text { Care } \\
\text { setting, } \\
\text { Duration }\end{array}$ & Intervention & Comparator & Analysis Test & Outcomes and Results \\
\hline $\begin{array}{l}\text { Yang Z, et al. } \\
\text { Acta Pharmacol } \\
\text { Sin. 2008;29: } \\
781-8 .\end{array}$ & $\begin{array}{l}27.57 \pm 5.76 \\
\text { years old } \\
\text { Heroin } \\
\text { dependence } \\
\text { by DSM-IV }\end{array}$ & $\begin{array}{l}\text { Inpatient, } \\
5 \text { months }\end{array}$ & $\begin{array}{l}\text { 1-THP } 60 \mathrm{mg} \\
\text { twice daily } \\
(\mathrm{n}=59)\end{array}$ & $\begin{array}{l}\text { Placebo twice } \\
\text { daily }(n=44)\end{array}$ & $\begin{array}{l}\cdot \text { Urine sample } \\
\text { - Heroin } \\
\text { Withdrawal Scale } \\
\text { (PAWS, scale } \\
\text { range: } 0-120 \text { ) }\end{array}$ & 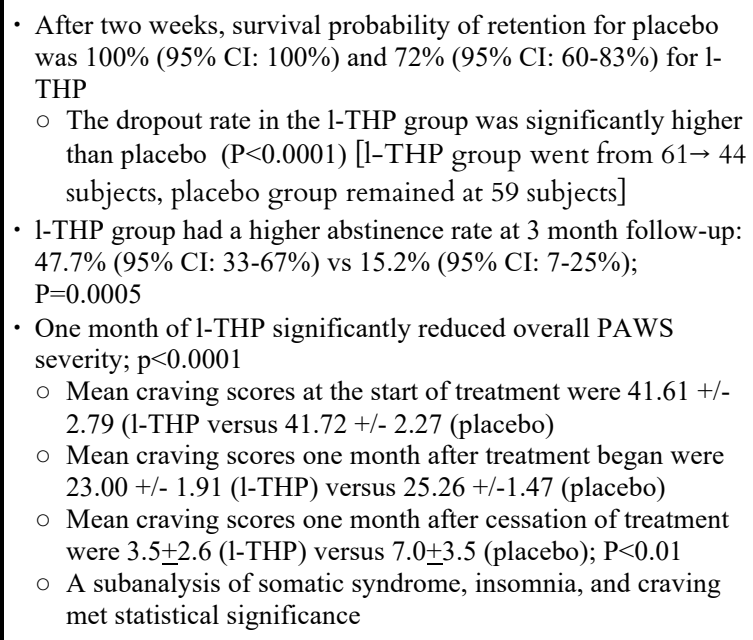 \\
\hline $\begin{array}{l}\text { Akhondzadeh } \\
\text { S, et al. J Clin } \\
\text { Pharm Ther. } \\
\text { 2001; 26: 369- } \\
73 \text {. }\end{array}$ & $\begin{array}{l}\cdot \text { Men only } \\
\cdot \text { DSM-IV } \\
\text { criteria for } \\
\text { opioid } \\
\text { dependence }\end{array}$ & $\begin{array}{l}\text { Outpatient, } \\
14 \text { days }\end{array}$ & $\begin{array}{l}\text { Clonidine, } \\
0.3 \mathrm{mg} \\
\text { increased to } \\
0.8 \mathrm{mg} \text { by day } \\
4, \text { plus } \\
\text { Passiflora } \\
\text { extract, } 60 \\
\text { drops per day } \\
\text { ( } \mathrm{n}=15)\end{array}$ & $\begin{array}{l}\text { Clonidine, } \\
0.3 \mathrm{mg} \\
\text { increased to } \\
0.8 \mathrm{mg} \text { by day } \\
4, \text { plus } \\
\text { Placebo, } 60 \\
\text { drops/day } \\
(\mathrm{n}=15)\end{array}$ & $\begin{array}{l}\text { SOWS (scale } \\
\text { range: } 0-30 \text { ) } \\
\text { - Expanded SOWS } \\
\text { to include mental } \\
\text { symptoms and } \\
\text { diarrhea (scale } \\
\text { range: } 0-48 \text { ) }\end{array}$ & $\begin{array}{l}\text { - Physical symptoms: both groups experienced a decrease in } \\
\text { scores, however differences between the groups were non- } \\
\text { significant } \\
\text { - Mental symptoms: both groups saw improvements in scores } \\
\text { over time. Statistically significant differences in scores favoring } \\
\text { passiflora extract were found beginning on the second day and } \\
\text { continuing to the end of } 14 \text { days, though no p value was } \\
\text { reported } \\
\text { O Clonidine group had significantly increased scores compared } \\
\text { to passiflora extract on days } 2,3,4,7,14 \\
\text { - Total scores: significantly decreased by both treatments, but the } \\
\text { total score by day } 14 \text { in the clonidine group was significantly } \\
\text { higher than the passiflora group ( }=0.011 \text { ) }\end{array}$ \\
\hline $\begin{array}{l}\text { Wen HL, et al. } \\
\text { Eur J } \\
\text { Pharmacol } \\
\text { 1982;82:183-6. }\end{array}$ & $\begin{array}{l}\text { 30-38 years } \\
\text { - Men with } \\
\text { chronic } \\
\text { heroin } \\
\text { abuse } \\
\text { - Relapse } \\
\text { history }\end{array}$ & $\begin{array}{l}\text { Inpatient, } \\
2 \text { hours }\end{array}$ & $\begin{array}{l}- \text { Dynorphin IV, } \\
60 \mathrm{mcg} / \mathrm{kg}, \\
\text { then saline IV } \\
\text { one hour later } \\
(\mathrm{n}=6) \\
\text { OR } \\
\text { - Saline IV then } \\
\text { dynorphin IV, } \\
60 \mathrm{mcg} / \mathrm{kg} \text {, on } \\
\text { hour later }(\mathrm{n}=6\end{array}$ & $\begin{array}{l}2 \text { injections of } \\
\text { IV saline given } \\
1 \text { hour apart } \\
(\mathrm{n}=6)\end{array}$ & $\begin{array}{l}\text { MKHP (scale } \\
\text { range: no upper } \\
\text { limit }\end{array}$ & $\begin{array}{l}\text { - Decreased withdrawal scores after dynorphin given as the first } \\
\text { injection }(0.01<\mathrm{P}<0.05 \text { ) } \\
\circ \text { A sustained decrease during the } 1 \text {-hr period after saline } \\
\text { injection }[\mathrm{P}<0.05 \text { (nurse assessment), } \mathrm{P}<0.02 \text { (patient } \\
\text { assessment)] } \\
\text { - Decreased score after dynorphin given as the second injection } \\
\text { whether compared to baseline or to the scores after saline given } \\
\text { as the first injection }\end{array}$ \\
\hline $\begin{array}{l}\text { Shi J, et al. Am } \\
\text { J Drug } \\
\text { Alcohol Abuse. } \\
\text { 2008; 34:792- } \\
800 .\end{array}$ & $\begin{array}{l}\text { 18-50 years } \\
\text { - Opiate } \\
\text { dependence } \\
\text { by DSM-IV }\end{array}$ & $\begin{array}{l}\text { ATC, } 10 \\
\text { days }\end{array}$ & \begin{tabular}{|l} 
Tapered \\
Jinniu: \\
Day 1-3: $2.5 \mathrm{~g}$ \\
three times \\
daily \\
Day 4-5: $2.0 \mathrm{~g}$ \\
three times \\
daily \\
Day 6-7: $1.5 \mathrm{~g}$ \\
three times \\
daily \\
Day 8-9: $1.5 \mathrm{~g}$ \\
twice daily \\
Day 10: $1.5 \mathrm{~g}$ \\
once (n=99)
\end{tabular} & $\begin{array}{l}\text { Tapered } \\
\text { lofexidine: } \\
\text { Day 1: } 0.4 \mathrm{mg} \\
\text { three times } \\
\text { daily } \\
\text { Day 2-5: } \\
0.6 \mathrm{mg} \text { three } \\
\text { times daily } \\
\text { Day 6-7: } \\
\text { 0.4mg three } \\
\text { times daily } \\
\text { Day } 8-9: 0.2 \text { or } \\
0.4 \mathrm{mg} \text { once } \\
\text { daily } \\
\text { Day 10: } 0.2 \mathrm{mg} \\
\text { (n=104) }\end{array}$ & $\begin{array}{l}\text { - Opioid } \\
\text { Withdrawal Scale } \\
\text { (scale range: } \\
\text { unknown) } \\
\text { - HAMA (scale } \\
\text { range: } 0-56 \text { ) }\end{array}$ & $\begin{array}{l}\text { - Total opioid withdrawal scale scores decreased for both groups, } \\
\text { but no significant difference between groups over the ten-day } \\
\text { course } \\
\text { - Main opioid symptom score reduction: no significant } \\
\text { differences between groups } \\
\text { - HAMA: no significant differences in anxiety reductions } \\
\text { between groups } \\
\text { Day 0: } 28.13+/-5.42 \text { (Jinniu) versus } 27.63+/-4.84 \\
\text { (lofexidine) } \\
\text { Day 5: } 9.45+/-5.93 \text { (Jinniu) versus } 8.96+/-5.38 \\
\text { (lofexidine) } \\
\text { Day 10: } 2.58+/-2.35 \text { (Jinniu) versus } 2.65+/-2.39 \\
\text { (lofexidine) }\end{array}$ \\
\hline
\end{tabular}




\begin{tabular}{|c|c|c|c|c|c|c|}
\hline $\begin{array}{l}\text { Wang, X, et al. } \\
\text { Am J Drug } \\
\text { Alcohol Abuse } \\
\text { 2009; 35: 408- } \\
11 .\end{array}$ & $\begin{array}{l}\text { 18-55 years } \\
\text { Heroin } \\
\text { dependence } \\
\text { by DSM-IV }\end{array}$ & $\begin{array}{l}\text { ATC, } 10 \\
\text { days }\end{array}$ & $\begin{array}{l}\text { Tapered FYP: } \\
\text { Day 1-3: } 6.0 \mathrm{~g} \\
\text { three times } \\
\text { daily } \\
\text { Day 4-6: } 8.0 \mathrm{~g} \\
\text { three times } \\
\text { daily } \\
\text { Day 7-10: } 8.0 \mathrm{~g} \\
\text { twice daily } \\
\text { plus matching } \\
\text { placebo } \\
(\mathrm{n}=104)\end{array}$ & $\begin{array}{l}\text { Tapered } \\
\text { lofexidine: } \\
\text { Day 1: } 0.4 \mathrm{mg} \\
\text { twice daily } \\
\text { Day 2-4: } \\
0.6 \mathrm{mg} \text { three } \\
\text { times daily } \\
\text { Day 5-6: } \\
0.4 \mathrm{mg} \text { three } \\
\text { times daily } \\
\text { Day 7-8: } \\
0.4 \mathrm{mg} \text { twice } \\
\text { daily } \\
\text { Day 9-10: } \\
0.2 \mathrm{mg} \text { twice } \\
\text { daily plus } \\
\text { matching } \\
\text { placebo } \\
\text { (n=103) }\end{array}$ & $\begin{array}{l}\text { - Withdrawal } \\
\text { syndrome rating } \\
\text { scale (scale range: } \\
\text { unknown) } \\
\text { - HAMA (scale } \\
\text { range: } 0-56 \text { ) }\end{array}$ & $\begin{array}{l}\text { Daily total withdrawal syndrome rating scale scores: both } \\
\text { groups had day by day significant decrease }(\mathrm{P}=0.0001) \\
\circ \text { Both groups met the effective threshold of }>50 \% \text { reduction } \\
\text { rate on day } 3 \text { (FYP: } 58.93 \% \text {, lofexidine: } 60.01 \%) \\
\circ \text { No significant difference between groups for daily total } \\
\text { scores or daily reduction rate } \\
\text { - Daily total HAMA score: no significant difference between } \\
\text { groups } \\
\text { - Adverse effects: lofexidine group ( } 42.34 \% \text { ) vs FYP group } \\
(14.29 \%)^{*} ; \mathrm{P}<0.001\end{array}$ \\
\hline $\begin{array}{l}\text { Kang L, et al. } \\
\text { Am J Drug } \\
\text { Alcohol Abuse } \\
\text { 2008;34: 269- } \\
76 .\end{array}$ & 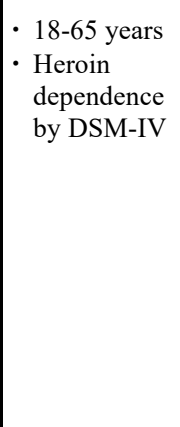 & $\begin{array}{l}\text { ATC, } 10 \\
\text { days }\end{array}$ & $\begin{array}{l}\text { Tapered TKN: } \\
\text { Day 1-5: } 2.0 \mathrm{~g} \\
\text { three times daily } \\
\text { Day 6-7: } 1.5 \mathrm{~g} \\
\text { three times daily } \\
\text { Day } 8-9: 1.5 \mathrm{~g} \\
\text { twice daily } \\
\text { Day 10: } 1.5 \mathrm{~g} \\
\text { once plus } \\
\text { placebo } \\
\text { lofexidine } \\
(\mathrm{n}=28)\end{array}$ & $\begin{array}{l}\text { Tapered } \\
\text { lofexidine: } \\
\text { Day 1: } 0.4 \mathrm{mg} \\
\text { twice daily } \\
\text { Day 2-5: } 0.6 \mathrm{mg} \\
\text { three times daily } \\
\text { Day 6-7: } 0.4 \mathrm{mg} \\
\text { three times daily } \\
\text { Day 8-9: } 0.2 \mathrm{mg} \\
\text { or 0.4mg once } \\
\text { Day 10: } 0.2 \mathrm{mg} \\
\text { plus placebo } \\
\text { (n=31) }\end{array}$ & $\begin{array}{l}\text { - Withdrawal } \\
\text { syndrome rating } \\
\text { scale (scale range: } \\
\text { unknown) }\end{array}$ & $\begin{array}{l}\text { - Daily total withdrawal syndrome rating scale scores: both } \\
\text { groups had day by day significant decrease }(\mathrm{P}=0.0001) \\
\text { O Both groups met the effective threshold of }>50 \% \text { reduction } \\
\text { rate on day } 3(\mathrm{TKN}: 55.94 \% \pm 16.24 \% \text { ) vs lofexidine: } \\
64.48 \pm 15.06 \%) \\
\text { No significant difference between groups for daily total } \\
\text { scores } \\
\text { - Adverse effects: TKN: } 62.5 \% \text { vs. lofexidine: } 65.6 \%\end{array}$ \\
\hline $\begin{array}{l}\text { Hao W, et al. } \\
\text { J Psychoactive } \\
\text { Drugs. } 2000 ; \\
32: 277-84 \text {. }\end{array}$ & $\begin{array}{l}\text { Heroin } \\
\text { dependence } \\
\text { by DSM-IV }\end{array}$ & $\begin{array}{l}\text { Inpatient, } \\
14 \text { days }\end{array}$ & $\begin{array}{l}\text { WeiniCom, } 8 \text { - } \\
10 \text { capsules } \\
\text { four to six } \\
\text { times daily, } \\
\text { gradually } \\
\text { tapered to zero } \\
\text { by day } 9-10, \\
\text { and matching } \\
\text { placebo }(n=21)\end{array}$ & $\begin{array}{l}\text { BUP 0.9- } \\
1.2 \mathrm{mg} \\
\text { intramuscularl } \\
\text { y twice daily, } \\
\text { tapered by } \\
0.3 \text { gm every } \\
\text { other day, and } \\
\text { matching } \\
\text { placebo }(\mathrm{n}=21)\end{array}$ & $\begin{array}{l}- \text { Withdrawal } \\
\text { Symptom Rating } \\
\text { Scale }(0-57) \\
\text { - Craving Rating } \\
\text { Scale (0-504) } \\
\text { - Side Effects } \\
\text { Rating Scale }(0- \\
\text { 57) }\end{array}$ & $\begin{array}{l}\text { - All patients retained for } 14 \text { days } \\
\text { - Withdrawal symptom scores decreased over time: } \\
\text { ○ Day 5, mean scores: } 19.4 \text { for BUP vs. } 12.6 \text { for WeiniCom; } \\
\mathrm{P}<0.05 \\
\text { Day } 6 \text {, mean scores: } 16.7 \text { for BUP vs. } 9.6 \text { for WeiniCom; } \\
\mathrm{P}<0.05 \\
\text { Day } 9 \text {, mean scores: } 15.2 \text { for BUP vs. } 5.2 \text { for WeiniCom; } \\
\mathrm{P}<0.05 \\
\text { - The decline in psychological craving was greater for } \\
\text { WeiniCom: } \\
\text { O Day 3: buprenorphine psychological rating score was } 100.0 \\
\text { versus } 43.3 \text { for WeiniCom; } \mathrm{P}<0.05 \\
\text { - Adverse effects were similar between groups } \\
\text { - No significant differences in blood, urine, liver, and kidney } \\
\text { function tests or electrocardiograms between groups }\end{array}$ \\
\hline
\end{tabular}

ATC = addiction treatment center, BUP= Buprenorphine, DSM= Diagnostic and Statistical Manual of Mental Disorders, FYP=Fu-Yuan Pellet HAMA= Hamilton Anxiety Scale ${ }^{19}$, MKHP=Modified Kolb and Himmelsbach procedure, SOWS= short opioid withdrawal scale, TKN= Tai-Kang-Ning *All adverse effects in the study resolved without treatment

\subsection{Results:}

Table 1 summarizes findings from the seven trials of integrative medicine identified for inclusion. Studies evaluated the use of integrative medicine approaches on multiple aspects of opioid withdrawal syndrome, including drug cravings, drug abstinence, and physical symptoms.

Trials were conducted primarily in an inpatient care setting and used different assessment scales, 
although all scales were focused on common OWS. All trials were randomized and six were double-blind while one trial employed a single-blind procedure. More than half of the trials used a standard of therapy for OWS as a comparator group or at baseline. Of note, an understanding of the natural course of opioid withdrawal, including that symptoms generally begin to decline after 3-5 days, is important to consider in evaluating the literature.

\subsubsection{Studies with a placebo comparator arm}

\section{Levo-tetrahydropalmatine (l-THP)}

Levo-tetrahydropalmatine (1-THP) is a traditional Chinese herb believed useful for drug craving and relapse with no abuse potential. ${ }^{7}$ One study evaluated the use of 1-THP for protracted opioid withdrawal syndrome (PAWS) after seven to ten days of detoxification among heroin users. Notably, participants were abstinent from opioids for at least seven days before beginning the trial. Subjects were randomized to receive $60 \mathrm{mg}$ of 1-THP or matching placebo twice daily for one month. Participants were evaluated for abstinence weekly through urine samples and for opioid withdrawal symptoms via the Heroin Withdrawal Scale during the active medication period and every two weeks thereafter for four months. The protracted abstinence withdrawal symptoms scale scored patients on symptoms in four categories: somatic, mood, insomnia, and heroin craving. The 1-THP group had a lower retention rate at the two-week treatment mark compared to placebo. The participants who persisted in the trial were more likely to be abstinent after three months when compared to the placebo group, suggesting the first two weeks of therapy pose the greatest risk of relapse. Additionally, treatment with 1-THP for one month was associated with a significant reduction in PAWS severity by the conclusion of the trial, specifically in regard to somatic syndrome, insomnia, and cravings. Study results indicated the 
importance of treatment past the typical one to two week window in which most patients experience withdrawal symptoms.

\section{Passionflower drops}

Passionflower (Passiflora incarnata) vine is known for its anxiolytic and sedative effects, recognized by the Commission E in 1995 and the British Herbal Compendium in $1996 .{ }^{10}$ One trial investigated the use of passiflora extract as an adjunct to clonidine for outpatient detoxification. ${ }^{10}$ Thirty medically healthy men with opioid dependence as defined by DSM-IV were given $0.8 \mathrm{mg} /$ day of clonidine divided into three daily doses and randomized to receive either 60 drops of passiflora extract or placebo three times daily for 14 days. The clonidine dose was tapered up from $0.3 \mathrm{mg} /$ day to $0.8 \mathrm{mg}$ /day in the first four days of the start of the trial. Further details of dosing were not provided by the study. Participants were assessed using the Short Opioid Withdrawal Scale (SOWS) expanded to include questions about mental symptoms and diarrhea. By day 14, both groups demonstrated a significant decrease in withdrawal symptoms based on the SOWS, but no significant difference was found between groups. However, a statistically significant difference was found between the two groups in regard to mental symptom scores, favoring the use of passiflora for mental symptoms, such as dysphoria, agitation, anxiety, and irritability. When taking into account SOWS scores, mental symptom scores, and diarrhea symptom scores, the placebo group had significantly increased mean total scores on day 14 than the passiflora group favoring the use of passiflora. Both the passiflora and placebo groups had large numbers of unexplained dropouts during the study, 15 and 20 participants, respectively. This trial may be too small and inadequately powered to adequately demonstrate efficacy for the addition of passionflower drops to clonidine for OWS.

\section{Dynorphin}


Dynorphin-(1-13) is a synthetic opioid agonist that has preliminary data on attenuating heroin withdrawal symptoms. ${ }^{11}$ In one trial, 18 men with longstanding heroin use were admitted to an inpatient care facility and randomized to one of three treatment groups upon demonstration of OWS. ${ }^{11}$ Two consecutive injections were given to patients one hour apart, either saline/saline, dynorphin/saline, or saline/dynorphin. The opioid withdrawal symptoms were scored using the Modified Kold and Himmelsbach procedure. Patients were scored for symptoms of opioid withdrawal every 15 minutes for one hour after each of the two injections. In both groups which received one $60 \mu \mathrm{g} / \mathrm{kg}$ injection of intravenous (IV) dynorphin, withdrawal scores were significantly decreased after injection. In the group that received a dynorphin injection first, saline did not result in any further lowering of opioid withdrawal score, however, scores remained low, suggesting a prolonged effect of dynorphin. In the group receiving the dynorphin injection second, withdrawal scores also decreased during the observation period. In regard to safety, three of the twelve patients displayed minor precordial formication, one reported feeling warm, and another dizzy.

\subsubsection{Studies with an active comparator arm:}

\section{Jinniu capsules}

One trial investigated the safety and efficacy of Jinniu capsules, a traditional Chinese medicine product containing a blend of eight herbs, compared to lofexidine, an alpha-2 adrenergic agonist, for OWS. ${ }^{6}$ Two hundred and twelve patients were randomized to a ten-day tapered regimen of Jinniu or lofexidine with tapering doses ranging from $7.5 \mathrm{~g}$ to $1.5 \mathrm{~g} / \mathrm{day}$ and $1.8 \mathrm{mg}$ to $0.2 \mathrm{mg} /$ day, respectively. Supplemental medications were allowed, including the use of estazolam and clonazepam. Patients were assessed via an Opiate Withdrawal Scale, with an 
emphasis on drug craving, lacrimation, anxiety, diarrhea, abdominal pain, bone and muscle ache, and insomnia as well as the Hamilton Anxiety Scale. Overall, opioid withdrawal symptoms and anxiety scale scores declined in the study and were similar between the groups. In terms of adverse events, Jinniu capsules were associated with blurred vision, dizziness, and dry mouth, while lofexidine was associated with dizziness, postural hypotension, and dry mouth.

\section{Fu-yuan pellet}

Fu-Yuan Pellet (FYP) is a ten herb traditional Chinese medicine product containing Largehead Atractylodes Rhizome, Hawthorn Fruit, Glabrous Greenbrier Rhizome, Tangshen, Prepared Dried Ginger, Eucommia Bark, Divaricate Saposhnikovia Root, Excrementum Pteropi, Desertliving Cistanche, and Dried Tangerine peel believed to be beneficial for OWS. ${ }^{8}$ One study compared the safety and efficacy of FYP versus lofexidine for symptoms of opioid withdrawal. ${ }^{8}$ Two hundred and twenty-five participants were randomized to receive a ten-day taper of FYP with doses ranging from $24 \mathrm{~g} /$ day to $16 \mathrm{~g} /$ day or lofexidine $1.8 \mathrm{mg} /$ day to $0.4 \mathrm{mg} / \mathrm{day}$. The $23-$ item withdrawal syndrome rating scale in the Principle of Clinical Trial of Anti-Opiate Withdrawal Drug was used to evaluate efficacy. ${ }^{9}$ Both treatments were considered effective as a score reduction of at least $50 \%$ was observed by the third day of treatment in both groups. Daily total scores, daily reduction rates, and total anxiety scale scores were similar between the two groups. Dry mouth was the most commonly reported adverse effect in both groups. Although lofexidine and FYP demonstrated similar efficacy, FYP was associated with significantly fewer adverse effects than lofexidine.

\section{Tai-Kang-Ning capsules}

Another study evaluated Tai-Kang-Ning (TKN) capsules, a blend of eight herbs hypothesized to aid opioid addiction recovery, against lofexidine for symptoms of opioid 
withdrawal. ${ }^{12}$ Sixty-four patients with acute heroin withdrawal were randomized to receive either TKN in a regimen tapering the dosage from $6 \mathrm{~g} /$ day to $1.5 \mathrm{~g} /$ day or lofexidine tapered from 1.8 $\mathrm{mg} /$ day to $0.2 \mathrm{mg} /$ day. Patients were evaluated using a withdrawal syndrome rating scale. Both treatments were considered effective because a withdrawal symptom score reduction rate of over $50 \%$ was observed by the third day of treatment in both groups. Furthermore, total scores for withdrawal syndrome decreased over the ten-day treatment course. Significant differences were not found between groups in either the daily total scores or the daily reduction rate.

\section{WeiniCom capsules}

WeiniCom, also known as Xuan Xia Qudu Jiaonang, is a blend of Chinese herbs including extracts of Glycyrrhiza glabra, Zingiber officinalis, Nauclea Spp, and Epimedium grandifora, among others. The product is believed to alleviate symptoms of opioid withdrawal in traditional Chinese and Ayurvedic medicine. ${ }^{13}$ One study evaluated the use of WeiniCom capsules compared to buprenorphine for the reduction in OWS and for adverse effects. ${ }^{14}$ Fortytwo subjects were randomized to treatment with either 8-10 capsules of WeiniCom four to six times daily, tapered to a dose of zero on treatment days nine and ten or buprenorphine $0.9-1.2 \mathrm{mg}$ intramuscularly twice daily in tailored doses, tapered by $0.3 \mathrm{mg}$ every other day until a dose of zero. In both arms, benzodiazepines (triazolam $0.75-2.5 \mathrm{mg} /$ day) were prescribed for patients with sleep problems or anxiety, the study reports that the use of benzodiazepines between groups was similar. Subjects were treated for 14 days. Both treatment and control groups experienced a decrease in Withdrawal Symptom Rating Scale scores and Craving Rating Scale scores over time. Significant differences between groups in regard to withdrawal symptoms were seen on days five, six, and nine of treatment in favor of WeiniCom. However, the assessments used were not validated at the time of the study. Furthermore, the trial failed to show significant findings 
consistently, rather, some treatment days were considered significant over others. These daily variances in significant findings have limited clinical applicability.

\subsection{Discussion:}

This systematic review was conducted to evaluate available evidence for the use of integrative medicine for the symptoms of opioid withdrawal. The integrative medicine approaches demonstrate potential benefits on selected symptoms of opioid withdrawal and in some studies, subsequent abstinence from opioid use, either as monotherapy or as an adjunct to clonidine, lofexidine, or buprenorphine. Passiflora and Tai-Kang-Ni were evaluated as adjunctive medications while Jinniu capsules, Fu-Yuan pellets, and WeiniCom were compared to prescription medications as monotherapy. Levo-tetrahydropalmatine and dynorphin were compared as monotherapy to placebo arms.

Both the intervention and comparator arms in each active-comparator trial included in this review demonstrated efficacy for opioid withdrawal symptoms, however the efficacy was often non-significant between study arms. Weinicom demonstrated significantly lower symptom scores than the comparator arm on multiple days, but the variances in statistical significance in day-to-day scores have limited clinical applicability. Similar safety profiles were seen for the integrative medicine approaches overall, except for Fu-Yuan pellets which had fewer adverse effects than the lofexidine comparator arm. A notable limitation of the active-comparator studies is the inadequate dosing of the comparator arms. For example, the lofexidine groups in the FYP, TKN, and Jinniu capsule trials may be considered underdosed. Current recommendations for the use of lofexidine in opioid withdrawal are $0.54 \mathrm{mg}$ four times daily for five to seven days. ${ }^{16}$ The studies utilized lofexidine $0.6 \mathrm{mg}$ three times daily as the maximum dose and this underdosing 
could contribute to a lack of significant findings. Additionally, the use of buprenorphine given as an intramuscular injection for OWS, as in the WeiniCom trial, is not indicated, thereby decreasing the trial's potential applicability. Furthermore, a number of trials allowed adjuvant medications such as benzodiazepines for patients having insomnia or agitation. The addition of adjuncts on outcomes was not expressly evaluated and should be considered as a potential confounder to the use of integrative medicines.

All of the placebo-comparator studies saw significant reductions in withdrawal symptoms of active treatment compared to placebo. The passionflower study suggested that passiflora may have favorable effects in regard to mental symptoms of opioid withdrawal specifically but concerns over the extensive number of unexplained dropouts may limit the applicability of the findings. The 1-THP study found improvements in overall PAWS and abstinence rates at the end of the three month trial for those who continued after the first two weeks of treatment. In the dynorphin study, participants demonstrated significantly decreased withdrawal scores after dynorphin administration, however the small study population may hinder the reliability of these findings and the participants were following for no longer than two hours, the shortest followup of all the trials. In the passiflora and 1-THP studies, data and discussion of adverse effects were lacking. The passiflora trial used clonidine in an appropriate dose, given current practice recommendations suggesting the use of clonidine in doses of $0.1 \mathrm{mg}-0.2 \mathrm{mg}$ two to four times daily. ${ }^{17}$

Overall, multiple assessment scales with varied follow-up periods were used to determine effectiveness for physical and/or mental symptoms of withdrawal. A comparison between treatments is difficult given the differences in the assessment. For example, the OWS and Kolb \& Himmelsbach procedures assess symptoms over a 24-hour period while the SOWS evaluates 
immediate responses. ${ }^{15}$ Thus, the definition of adequate follow-up for integrative medicine approaches remains uncertain.

The participants in the trials varied in their duration of opioid use disorder, additional substance misuse, and time since last use. In general, trials had a small patient population composed primarily of men. Both the passionflower and dynorphin studies only used male participants, while the WeiniCom, 1-THP, TKN, and Jinniu studies had 88\%, 75\%, 83\%, and 86\% male participants, respectively. The FYP study did not delineate between male and female participants. Most of the trials had fewer than 100 participants and a short duration of follow up, warranting larger studies including a larger proportion of women to validate initial findings.

Availability and feasibility of administration are also potential limitations of integrative medicine approaches. For example, of the approaches mentioned, dynorphin would be a more burdensome treatment option for patients because of the need for IV administration. The overall safety, efficacy, and availability of integrative medicines cannot be guaranteed given potential variances in the authenticity and purity of products resulting from a lack of governmental regulation and pharmacopeial standards.

Preliminary literature searches identified a large body of evidence for the use of acupuncture to relieve opioid withdrawal symptoms. Because of the widespread availability of studies, systematic reviews, and meta-analyses involving acupuncture as well as the complexity of technique, those studies were excluded. Although this study aimed to evaluate lesser-known integrative medicine approaches, the elimination of analysis of acupuncture as an integrative medicine approach may be considered a limitation to this review. Additionally, despite the popularity of ibogaine and kratom, we did not identify studies with either natural product that met our inclusion criteria. 
Despite the limitations, integrative medicine may have the potential for alleviating opioid withdrawal symptoms. In general, outcome measures improved over time but were confounded by the natural course of opioid withdrawal resolution, specific characteristics of drug dependency, and individual determination in recovery. The results of this systematic review support the need for further research on integrative medicine for symptoms of opioid withdrawal.

\subsection{Conclusions:}

Limited data demonstrates that integrative medicine has potential benefits in lessening opioid withdrawal symptoms without increasing the risk of adverse effects. Additional trials with larger patient populations are necessary to provide stronger evidence to support the use of integrative medicine approaches for OWS. Trials which focus on the feasibility of integrative medicine as monotherapy for outpatient treatment may be of particular value. Further research is necessary to adequately determine reliable approaches for opioid withdrawal symptoms.

\subsection{Disclosures and Acknowledgments:}

The authors of this systematic review have no affiliations to disclose nor competing interests. This research did not receive any specific grant from funding agencies in the public, commercial, or not-for-profit sectors.

\section{Resources:}

1. Centers for Disease Control and Prevention. U.S. Opioid Prescribing Maps. Available at: https://www.cdc.gov/drugoverdose/maps/rxrate-maps.html. Accessed March 8, 2020.

2. American Addiction Centers. Opiate Withdrawal Timelines, Symptoms and Treatment. Available at: https://americanaddictioncenters.org/withdrawal-timelinestreatments/opiate. Accessed March 9, 2020 
3. American Society of Addiction Medicine. The ASAM National Practice Guideline for the use of medications in the treatment of addiction involving opiate use. Available at: https://www.asam.org/docs/default-source/practice-support/guidelines-and-consensusdocs/asam-national-practice-guideline-supplement.pdf. Accessed March 9, 2020

4. Kosten TR, Baxter LE. Review article: Effective management of opioid withdrawal symptoms: A gateway to opioid dependence treatment. Am J Addict. 2019 Feb;28(2):5562. doi: 10.1111/ajad.12862.

5. Jadad AR, Moore RA, Carroll D, et al. Assessing the quality of reports of randomized clinical trials: is blinding necessary? Control Clin Trials. 1996;17(1):1-12.

6. Shi J, Xu GZ, Liu TT, et al. A comparative clinical study of the effects of the traditional Chinese medicine Jinniu capsules and lofexidine on acute heroin withdrawal symptoms. Am J Drug Alcohol Abuse. 2008;34(6):792-800. doi: 10.1080/00952990802491563.

7. Yang Z, Shao Y, Li S, et al. Medication of 1-tetrahydropalmatine significantly ameliorates opiate craving and increases the abstinence rate in heroin users: a pilot study. Acta Pharmacol Sin (2008)29:781-788. doi:10.1111/j.1745-7254.2008.00817.

8. Wang X, Li J, Huang M, et al. A study on Fu-Yuan Pellet, a traditional Chinese medicine formula for detoxification of heroin addictions. Am J Drug Alcohol Abuse. 2009;35(6):408-11. doi: 10.3109/00952990903377146.

9. Lei G. Controlled Study of Detoxificated Effect of Fuyuan Pellet and Lofexidine Hydrochloride on Opiate Withdrawal Symptoms. Master paper 2007; 1-22.

10. Akhondzadeh S, Kashani L, Mobaseri M, et al. Passionflower in the treatment of opiates withdrawal: a double-blind randomized controlled trial. J Clin Pharm Ther. 2001 Oct;26(5):369-73. 
11. Wen HL, Ho WK. Suppression of withdrawal symptoms by dynorphin in heroin addicts. Eur J Pharmacol. 1982 Aug 27;82(3-4):183-6.

12. Kang L, Li B, Gao L, et al. Tai-Kang-Ning, a Chinese herbal medicine formula, alleviates acute heroin withdrawal. Am J Drug Alcohol Abuse. 2008;34(3):269-76. doi: 10.1080/00952990802013409.

13. Doosti F, Dashti S, Tabatabai SM, et al. Traditional Chinese and Indian medicine in the treatment of opioid-dependence: a review. Avicenna J Phytomed. 2013;3(3):205-215.

14. Hao W, Zhao M. A comparative clinical study of the effect of WeiniCom, a Chinese herbal compound, on alleviation of withdrawal symptoms and craving for heroin in detoxification treatment. J Psychoactive Drugs. 2000 Jul-Sep;32(3):277-84.

15. Nuamah JK, Sasangohar F, Erraguntla M, Mehta RK. The past, present and future of opioid withdrawal assessment: a scoping review of scales and technologies. BMC Med Inform Decis Mak. 2019 Jun 18;19(1):113. doi: 10.1186/s12911-019-0834-8.

16. Lofexidine. In: IBM Micromedex ${ }^{\circledR}$ DRUGDEX ${ }^{\circledR}$ (electronic version). IBM Watson Health, Greenwood Village, Colorado, USA. Available at: https://www.micromedexsolutions.com/ (cited: April 20, 2020).

17. Clonidine. In: IBM Micromedex ${ }^{\circledR}$ DRUGDEX® (electronic version). IBM Watson Health, Greenwood Village, Colorado, USA. Available at: https://www.micromedexsolutions.com/ (cited: April 20, 2020).

18. Withdrawal Syndrome Rating Scale. Principle of Clinical Trial of Anti-opiate Withdrawal Drug. Ministry of the Health of the People's Republic of China, 1994; October 10-11. 
19. Hamilton M. The assessment of anxiety states by rating. Br J Med Psychol 1959; 32:5055. 